\title{
Nitrate Control Technical Progress in Water Treatment
}

\author{
Lei Fang ${ }^{2}$, Qi Zhu* ${ }^{1}$ \\ ${ }^{1}$ School of Chemistry and Material Sciences, Heilongjiang University, Harbin, China \\ ${ }^{2}$ College of Life and Chemistry, Harbin University, Harbin, Chinace
}

\begin{abstract}
Leaching of nitrate compound ground runoff loss and nitrogen element, resulting in the pollution of groundwater. Most areas in China with the groundwater as drinking water, consume excessive amounts of nitrate the damage to the human body is various, therefore, removal of nitrate in water is urgent. At present, the conventional method has certain advantages and limitations, the imminent is innovation, more advantages and stronger control technology and strengthen research and improve the original method. Through research water nitrate pollution and its harm, this paper summarizes some regular removal of nitrate in water technology principle, and improved, and put forward the thought of the combination process, the process is the most important advantage of the level of play. Also an analysis of the current control of nitrate in water technology present situation and development trend of the technology at home and abroad.
\end{abstract}

\section{Introduction}

Red Agricultural fertilizer, sewage and infiltration of industrial wastewater and solid waste containing nitrogen, atmospheric sedimentation and backflow of sewage and so on, will cause the water nitrate concentration increase. A huge mass of data show that the use of chemical fertilizer has caused a global pollution, nitrate leaching loss and nitrogen compounds of surface runoff, groundwater and surface water is an important cause of pollution.

Study on the groundwater resources of nitrogen pollution in China began in 1980s. But in the early 60's before and after the "underground water", "underground water", is the nitrate pollution of groundwater. According to the study of groundwater in 50 areas in China since 1978, 21 cities have been polluted by nitrate, especially in the north. Through the water quality monitoring of 69 counties, more than half of the maximum allowable amount of nitrate in drinking water, the World Health Organization in 1958, the international standard for drinking water, the content of nitrate in drinking water, the content has been strictly limited. People realize that the harm to human body is also found in groundwater irrigation with excessive nitrate. The problem of nitrate pollution is becoming an urgent problem, which makes it a great challenge to mankind. Prolapse of nitrate in water is designed to maintain as the main source of drinking water safety of underground water, it is necessary to carry out the prevention and control of groundwater pollution. On the other hand, in order to better control the surface water pollution, it should also carry out the work of pollution control. Although in recent years our country has done a lot of work in groundwater pollution prevention and control, but most of these work to control the main, no mechanism and contribution to the water pollution.

Nitrate compound to the harm of the person, consuming too much damage there is a lot of aspects of nitrate to human body. Acid salt have expansion effect to the peripheral vascular. Long time drinking excessive water nitrate content, nitrite accumulation to the human body, once the accumulation reaches a certain extent, genetic mutations can result in deformity, even lead to cancer. Excessive nitrate intake can also lead to human activities, decreased ability to work, dizziness, coma. People aware of the dangers of excessive amounts of nitrate to human body, also found a wine containing an excessive amount of nitrate groundwater irrigation, also not small impact on plant growth. The meaning of the emergence of nitrate in water is security as the main source of drinking water safety of ground water, groundwater pollution prevention and control are needed in the work. In this paper, we study the water nitrate control technology research and development prospects, to find the feasible method to minimize the content of nitrate in water.

\section{Nitrate pollution and its harm}

\subsection{The characteristics of nitrate}

Nitrate is soluble in water. General is not stable, can decompose when heated, and oxygen release, therefore, at high temperature, as oxidant. Nitrate activity of metal elements in different decomposition product is different. In order metal activity between magnesium and copper nitrate, heat decomposition with metal oxides, nitrogen dioxide and oxygen. Magnesium nitrate, decomposition product is nitrite and oxygen, copper nitrate after breakdown products are metal elemental, nitrogen dioxide and oxygen. Nitrate can be explosive and nitrogen fertilizer.

In water purification process, ammonia nitrate and nitrite nitrogen effect generated through digesting. Some active metal nitrates can be formed after heated, and nitrite amine material combination, can form a strong carcinogenic nitrosamines. Nitrate to nitrite class of compounds with strong carcinogenic properties of synthetic provides a material basis. Nitrosamines can induce the digestive system diseases.

Ammonia quickly under the action of the nitrifying bacteria, denitrifying bacteria, under aerobic conditions to ammonia nitrogen oxide into nitrate and nitrite, called nitration. Nitrate and nitrite in the case of the outside source of organic carbon, by denitrifying bacteria called nitrate and nitrite reduction of nitrogen denitrification. In 
water purification process, ammonia nitrate and nitrite nitrogen effect generated through digesting. Some active metal nitrates can be formed after heated, and nitrite amine material combination, can form a strong carcinogenic nitrosamines. Nitrate to nitrite class of compounds with strong carcinogenic properties of synthetic provides a material basis. Nitrosamines, it can cause the digestive system diseases. Liver cancer mortality is higher in nantong, jiangsu province, with local nitrate and nitrite content is higher in drinking water has to be reckoned with.

\subsection{Nitrate pollution}

Nitrate pollution is mainly due to the production life of mankind, the pollution of nitrate in the same way. Factors influencing the groundwater nitrate exist mainly include the following: the overuse of agricultural nitrogen fertilizer, residents use does not handle the sewage discharge, industrial wastewater containing nitrogen leak, leaching of solid waste, water recharge again, atmospheric precipitation infiltration will make unit groundwater nitrate content increased [1]. There are universal existence of nitrate pollution of groundwater, and has become a major problem[2].

\subsection{The harm of nitrate}

Enter human body through drinking water or food nitrates, although most will be out of the body along with urine, but the other $20 \%$ will be stored in the body. After the nitrate in the human body, through the function of the digestive system converts nitrite nitrogen, nitrite nitrogen could combine with the formation of methemoglobin hemoglobin. Lose the ability of blood oxygen, causing difficulty in breathing, or even kill patients. Infants and young children because of the body development is not mature, are more likely to cause disease. Due to the water quality for a long time drinking excessive amounts of nitrate, cause baby of methemoglobin. Abundant accumulation of nitrate in the human body, or death, but most of the harm of human body is not easy to detect.

\section{Nitrate control technology}

\section{1 membrane separation}

Membrane separation principle is through extra impetus, the membrane separation of components on both sides of your goal, commonly used for groundwater nitrogen membrane separation include reverse osmosis and electrodialysis.

\section{(1) Reverse osmosis}

The reverse osmosis membrane was in direct proportion to the removal rate of various ions, but it had no selectivity to nitrate. Reverse osmosis in the removal of nitrate can also remove other inorganic salts, so the reverse osmosis method will reduce the degree of water. Using three cellulose acetate membrane, reverse osmosis membrane, the reverse osmosis system of the nitrate and the polyamide membrane was studied. To prevent membrane fouling by adding six sodium phosphate and sulfuric acid into the water[3].

\section{(2) Electroosmosis}

The principle of electrodialysis using ion selective removal of semipermeable membrane, the nitrate concentration decreased to below the standard. Advantages of electrodialysis is without the use of any other chemicals[4], and reverse osmosis nitrogen removal efficiency is equal, the two methods of cost substantially the same.

\subsection{Biological denitrification method}

Biological denitrification method, also known as biological denitrification, due to the characteristics of high efficiency and low consumption, is considered the most potential denitrification method. Also get a wide range of attention process will be $\mathrm{NO}_{3}{ }^{-}$or $\mathrm{NO}_{2}^{-}$reduction to gaseous nitrogen oxide $\mathrm{NO}$ and $\mathrm{N}_{2} \mathrm{O}$. Autotrophic denitrification because without the need of additional organic matter. The effluent containing no organic carbon pollution, it is the utilization of groundwater in the presence of inorganic carbon source (such as $\mathrm{CO}_{2}$ and $\mathrm{HCO}_{3}^{-}$) or plus sulfur and hydrogen as an energy source for nitrogen removal. But the disadvantage is that the unit volume of the reactor is small. Heterotrophic denitrification requires organic carbon (e.g. methanol) as a source of nutrients and electron donor. The advantages of large amount of treatment, fast; the disadvantage is the lack of investment, will lead to the accumulation of nitrate in the water, the addition of organic matter, leaving the organic substrate to be treated water will produce two pollution, if become drinking water, the follow-up of complex processing is necessary.

The biological denitrification process has been used for many years, but some shortcomings still exist. For example, the operation management requires high technology, and the treatment of water can have different degrees of pollution, but also need to be treated.

Biological denitration technology has been used for years, but there are still some shortcomings. Operation management, for example, requires high technology, and the processing of water can have different degrees of pollution, but also to deal with.

\subsection{Chemical denitrification method}

In the early 1990s, the research on the technology of chemical catalytic denitrification was on the rise. $\mathrm{H}_{2}$ was used as a reducing agent, the nitrate reduction[5]. In recent years, domestic and foreign scholars pay close attention to it. It is a method to remove nitrate from drinking water. Under the premise of the catalyst, H2 clean and harmless as a reducing substance, can be reduced to $\mathrm{N}_{2}$ or $\mathrm{NH}_{4}{ }^{+}-\mathrm{N}$. In the elimination of pollution has a higher total and efficient advantages. As long as the catalyst and reaction conditions are reasonably selected, the method can be used in theory, and the nitrate can be reduced to $\mathrm{N}_{2}$. Because of using hydrogen as the reducing agent but also on the water to be treated is caused by 
secondary pollution, so the process can be in groundwater quality and water conditions better under, the principle of this process has also been a lot of attention degree, and is considered to be a good developmental prospect of nitrogen removal process. The choice of catalyst is very important, and the noble metals have high activity and good selectivity, such as Pd, Rh, Pt, Ir, Ru, etc.. Under the action of the catalyst, the reduction of $\mathrm{NO}_{3}{ }^{-} \mathrm{N}$ to $\mathrm{N}_{2}$, reducing the efficiency of $98 \%[6]$, is a catalytic method for removing nitrate. Pd, Pt and Rh were used as catalysts for the reduction of nitrate in groundwater, and the effect of Rh was the best[7], which can make the concentration of nitrate from L $40 \mathrm{mg} /$ to $11 \mathrm{~L} \mathrm{9mg/,} \mathrm{and} \mathrm{the} \mathrm{presence} \mathrm{of}$ nitrate was not detected. $\mathrm{H}_{2}$ was used to remove nitrate from the $\mathrm{Al}_{2} \mathrm{O}_{3} \mathrm{Pd}-\mathrm{Cu} /$ and tubular ceramic membrane. The catalytic removal of $\mathrm{NO}_{3}{ }^{-} \mathrm{N}$ was very effective, and the total removal rate of nitrate was $81 \%$. To increase the activity of catalyst and the selectivity of nitrogen, the reaction conditions are better controlled to reduce the byproducts. How to improve the mass transfer efficiency in the process of catalytic reduction and the recovery and separation of the catalyst is the key to solve the problem.

In alkaline environment, some metals (such as $\mathrm{Al}, \mathrm{Fe}$, Cd, etc.) can be used to restore nitrate. The most research topic is the reduction of iron powder. As a reducing agent, the attempt to remove nitrate from water in 1964, due to the need to constantly adjust the $\mathrm{pH}$ value of the reaction, and about $75 \%$ of the nitrate conversion to $\mathrm{N}-\mathrm{NH}_{4}{ }^{+}$. This method is considered to be a promising application in the treatment of large scale drinking water. Since 1990, iron reduction method has been concerned. Under aerobic conditions, iron powder was reduced by nitrate reduction in different $\mathrm{pH}$ conditions. To adjust the $\mathrm{pH}$ value and the acid value of the buffer in the process of reflection $\mathrm{pH}$. The use of $\mathrm{Fe} 0$ reducing agent in the treatment of Landfill Leachate Polluted Groundwater effect is good, studies show that total nitrogen content from $50 \mathrm{mg} / \mathrm{L}$ below 10 $\mathrm{mg} / \mathrm{L}$ and $\mathrm{N}-\mathrm{NH}_{4}{ }^{+}$removal rate reached 78\% 90\%. It is suggested that the use of zinc as a reducing agent to reduce the nitrate in wastewater is a method, and applied for a patent. Reduction of nitrate between $9<\mathrm{pH}<10$ with pH. The main products of $60 \% \sim 90 \% \mathrm{~N}^{-\mathrm{NH}_{4}}{ }^{+}$, a part of the reduction of nitrate and $\mathrm{N}_{2}$.

\subsection{Physical and chemical nitrogen method}

Removal of nitrate by ferrous compounds has been proposed, but the results show that the cost is very high, and it takes a while to apply it [8]. Due to the usually can cause the $\mathrm{pH}$ value increased to 9.1 or above with lime, adjusting the $\mathrm{pH}$ value of the required cost is low, so effectively use the technology can be applied in the lime for softening water treatment plant.

It is very difficult to deal with the conventional ion exchange resin for nitrate in the brine. The presence of sulphate in water reduces the ability of the resin to remove nitrate, since the first exchange of all the water in the water, and the nitrate in the water, to solve this problem requires the use of a priority of nitrate. This kind of resin first exchange nitrate is not affected by water, and the exchange capacity of nitrate is high. The process will be in the water of nitrate and other salt is actually equivalent to the concentration of the waste water in the. The method of ion exchange denitrification is suitable for the treatment of groundwater in small and medium cities. A year in the test scale of ion process for when compared with ion exchange craft factory investment cheaper biological nitrogen removal plant 2.5 3 times[9], operation cost also than the latter slightly cheaper methods of nitrogen desalting process plant and biological exchange over. France in 1985, 6 of the use of ion exchange plant operation process, the total processing capacity can reach 576 cubic meters / hour[10]. In 1990, the British ion exchange processing plant was officially run, is the first of the United Kingdom to use resin as a nitrate selective resin, used for resin regeneration every day need 1000 kilograms of salt.

$\mathrm{CaCO}_{3}$ precipitation can be controlled by the addition of acid, and calcium carbonate precipitation can be observed in the ion exchange column and in the pipeline. There is an ion exchange process to remove nitrate from the factory, processing capacity to reach the operation of $155 \mathrm{~m}^{3} / \mathrm{h}$, the results show that: the total consumption of salt a year of 250 tons. So it would be a very important problem to dispose of a large amount of waste water.

The two processes of ion exchange and biological denitrification can be combined, which can effectively eliminate some problems in a single process. Biological denitrification process of the effluent, the presence of microorganisms and organic pollutants in the water must be removed after a follow-up treatment. And ion exchange process for resin regeneration need to consume a lot of $\mathrm{NaCl}$ solution $(55 \sim 110 \mathrm{~g} / \mathrm{L})$, the regeneration of the need for further disposal of waste, the waste liquid usually contains high concentrations of $\mathrm{SO}_{4}{ }^{2-}, \mathrm{Cl}^{-}, \mathrm{NO}_{3}{ }^{-}$, thereby increasing the number of operating costs.

Germany built a factory with the above ion exchange process and the ability to deal with the strong, the amount of carbon dioxide dissolved in water, the reaction to the left to move, so that resin regeneration; when carbon dioxide concentration in the water, the reaction to the right side into the line, so as to remove the nitrate, sulfate and hardness of water.

It was found that the ratio of the chloride to the alkalinity of the ordinary resin effluent was higher than that of the nitrate selective resin. Ion exchange resin to remove neutral salt from the solution and release the same amount of carbon dioxide. Compared with the traditional ion exchange process, the process is not to increase the amount of salt in the effluent of the regeneration agent. Therefore, only the need to discharge in the exchange process of salt removal. Ion exchange process with carbon dioxide as a regenerative agent, it has the advantage of not producing an excess of two times of regeneration. Moreover, carbon dioxide can be used repeatedly, and the amount of recycled agent has also been saved. The disadvantage of this process is that the process is more complex, and there are some difficulties in operation management. In addition, carbonate is a kind of weak acid, the dissociation of the proton and bicarbonate ion concentration is very low, resulting in a resin regeneration was not completely. 


\section{The development trend Nitrate control technology}

At present, it is urgent to innovate more and more advantages and to strengthen the research and improve the existing technology, and now the application of the method has certain advantages and limitations.

Biological denitrification is the best method to be put into practice at present, in the two aspects of efficiency and cost. But there are still some problems, such as not suitable for dispersing or small water treatment, need to follow-up treatment, management requirements higher. Therefore, it has been developed a new and efficient method to remove nitrate in the research. It has a certain advantage in automatic control, reducing the two time processing and so on.

The chemical catalytic denitrification method has the advantages of low reaction speed, and has the potential of the economy, the requirements of the operation management and the strong adaptability to the dispersion or small water supply. But the study on the reduction of nitrate by chemical denitrification is not deep enough, still need to explore the unknown factors are still a lot of. The difficulty of this technique is that the activity, selectivity and stability of the catalysts are difficult to control. In the process of reaction, it is possible that the reaction can not be completely converted to nitrite, or because of the strong hydrogenation, some by-products are formed. Because of its unique advantages, catalytic denitrification has attracted much attention, chemical catalytic reduction method and biological treatment method, can be completely reduced to nitrogen, but different from biological treatment method, the treatment rate of nitrate technology is faster than catalytic reduction method.

Catalytic denitrification in the future should be to improve the activity and selectivity of the catalyst for the direction, focus on the following three objectives: (1) improve the $\mathrm{pH}$ buffer effect around the active site. Catalytic denitrification process will produce hydroxyl ions and $\mathrm{pH}$ value has a particularly large impact on the catalytic selectivity, thus ensuring the reaction when the $\mathrm{pH}$ is always maintained within an optimal range. For the catalytic denitrification is difficult. (2) improve catalyst support and reduce the amount of precious metals. (3) finding alternative hydrogen donors, using the method of electrolysis for hydrogen, also becomes a research direction. Soluble in water, but can be converted into nitrite, the human body and animal and plant to produce a considerable damage, economic losses are self-evident.

\section{Conclusion}

In this paper, through research on groundwater pollution situation and its removal from the analysis of the technology, biological denitrification and chemical catalytic denitrification method is the widely used method, but the advantages and disadvantages of each of each process is carefully choose corresponding method to deal with different waters is the key to achieve good treatment effect. And summarizes some combination process, this kind of technology can avoid some problems that exists in a single process, the technology advantage of effective play out, but also can avoid the limitations of a single process. Research and develop some efficient and low consumption, is suitable for the removal of nitrate in water application technology is critical.

\section{Acknowledgements}

This work was supported by the Natural Science Foundation of Heilongjiang Province (E201456), 2015 college students' innovative entrepreneurial training project plan of Heilongjiang Province (201510212949), 2014 innovation Foundation of Key Laboratory of Chemical Engineering Process \& Technology for Highefficiency Conversion (20140302).

\section{References}

[1] C. Xiang. Nanjing Forestry University master's thesis.(2008)

[2] O. Gibert. Bioresource Technology. (2008)

[3] C. JingHua. Ocean University of China master's thesis. ( 2006 )

[4] D. Bouchard, M. Willams, R. Suranpalli. American Water Assoc.( 1992)

[5] V. Mat eju. En zyme Microb T echnol. (1992)

[6] H. oor old S, T. acke T, K. Vorlop. Environ. T echnol. (1993)

[7] J. Reddy Kat ta, L. Jianping. Water Research. (2000)

[8] T. Sorg. J. AWWA. (1987)

[9] R. Eliassen, B. Wyckoof, C. Tonkin. J. AWWA. (1965)

[10] Y. Richard. J. Inst. Water Environ Mgmt. (1989) 